\title{
POSISI PEMIKIRAN FEMINIS FAQIHUDDIN DALAM PETA STUDI ISLAM KONTEMPORER
}

\section{Ulfah Zakiyah}

Alumni Pascasarjana UIN Syarif Hidayatullah Jakarta ulfahzakiyah1@gmail.com

\section{أبستر (أك}

ثينيليتييان إيني فوكوس مبغكاجي قوسيسي قيميكيران فيمينيس فقيه الدّين عبد

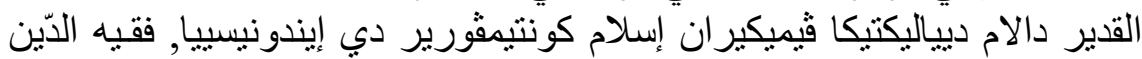

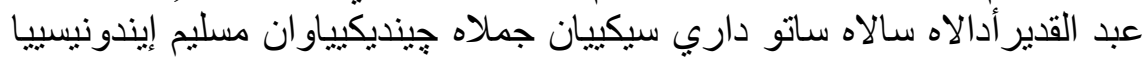

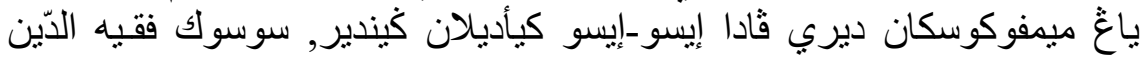

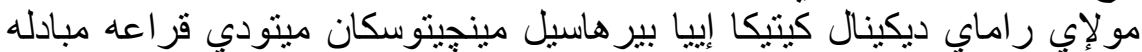

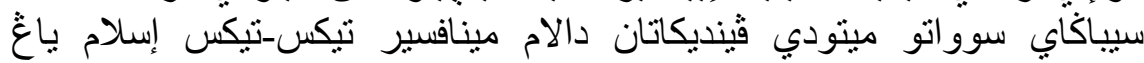

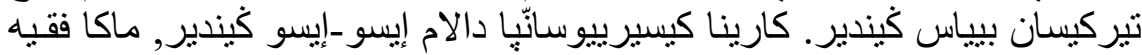
الدّين سيريخ دي سييوت سيباكاي فيمينيس, ليبيه تيثاتيا سيباكاي فيمينيس مسليم.

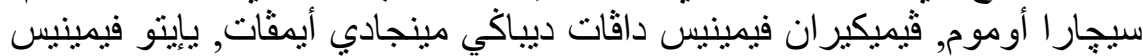
ليبير ال, فيمينيس سوسيياليس, فيمينيس ر اديكال, دان فيمينيس قوست فئموديرنيس.

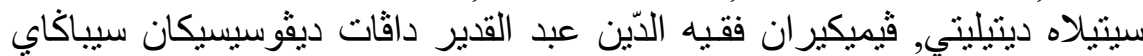

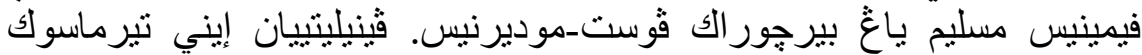

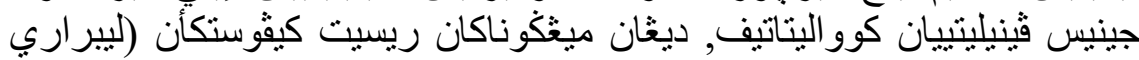

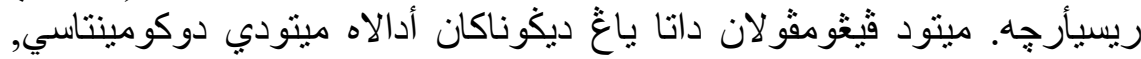




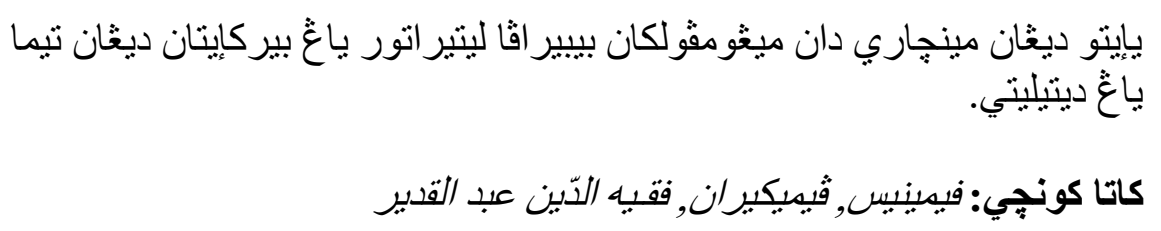

\begin{abstract}
Abstrak
Penelitian ini fokus mengkaji posisi pemikiran feminis Faqihuddin Abdul Kodir dalam dialektika pemikiran Islam kontemporer di Indonesia. Faqihuddin Abdul Kodir adalah salah satu dari sekian jumlah cendikiawan Muslim Indonesia yang memfokuskan diri pada isu-isu keadilan gender. Sosok Faqihuddin mulai ramai dikenal ketika ia berhasil mencetuskan metode Qira'ah Mubadalah sebagai suatu metode pendekatan dalam menafsir teks-teks Islam yang terkesan bias gender. Karena keseriusannya dalam isu-isu gender, maka Faqihuddin sering disebut sebagai feminis, lebih tepatnya sebagai feminis Muslim. Secara umum, pemikiran feminis dapat dibagi menjadi empat, yaitu feminis liberal, feminis sosialis, feminis radikal, dan feminis post-modernis. Setelah diteliti, pemikiran Faqihuddin Abdul Kodir dapat diposisikan sebagai feminis muslim yang bercorak post-modernis. Penelitian ini termasuk jenis penelitian kualitatif, dengan menggunakan riset kepustakaan (library research). Metode pengumpulan data yang digunakan adalah metode dokumentasi, yaitu dengan mencari dan mengumpulkan beberapa literatur yang berkaitan dengan tema yang diteliti.
\end{abstract}

Kata Kunci: Feminis, Pemikiran, Faqihuddin Abdul Kodir

\title{
Abstract
}

This study focuses on examining the position of Faqihuddin Abdul Kodir's feminist thought in the dialectic of contemporary Islamic thought in Indonesia. Faqihuddin Abdul Kodir is one of a number of Indonesian Muslim scholars who focus on gender justice issues. The figure of Faqihuddin became popular when he succeeded in initiating the Qira'ah Mubadalah method as an approach to interpreting Islamic texts that seemed gender biased. Because of his seriousness in gender issues, Faqihuddin is often referred to as a feminist, more precisely a Muslim feminist. In general, feminist thought can be divided into four, namely liberal feminists, socialist feminists, radical feminists, and post-modernist 
feminists. After researching, Faqihuddin Abdul Kodir's thoughts can be positioned as a Muslim feminist with a post-modernist style. This research is a qualitative research, using library research. The data collection method used is the documentation method, namely by finding and collecting some literature related to the theme under study.

Keywords: Feminist, Thought, Faqihuddin Abdul Kodir 


\section{Pendahuluan}

ampai saat ini feminisme masih menjadi salah satu isu yang hangat diperbincangkan sehari-hari oleh masyarakat dunia, termasuk di Indonesia. Istilah feminisme merujuk pada satu gerakan dan pemikiran yang mempertanyakan, mengkiritik sekaligus menuntut pemenuhan hak-hak dan keadilan gender. Kritik kaum feminis diarahkan kepada masalah perlakuan yang tidak adil terhadap perempuan dengan mendapat perlakuan diskriminasi, subordinasi, kekerasan, dan alenasi sosial.

Sebagai respon terhadap perlakuan yang tidak adil terhadap perempuan, maka munculah beberapa tokoh yang membebaskan perempuan dari jeratan budaya patriarki. Tokoh-tokoh tersebut kemudian digelari dengan istilah feminis, gelar tersebut dilekatkan kepada mereka sebagai tanda bahwa mereka adalah tokoh pembebasan bagi perempuan. Terdapat beberapa nama yang akrab di telinga seperti Fatimah Mernissi, Qasim Amin, Amina Wadud, Asghar Ali Engineer, Nawal El-Saadawi, Riffat Hasan, dan masih banyak lagi yang lain. Mereka adalah tokohtokoh yang berkontribusi besar dalam merubah tatanan masyarakat kea rah yang berkeadilan gender.

Selain itu, terdapat juga tokoh-tokoh di Indonesi yang muncul dipermukaan sebagai tokoh yang dikenal sebagai feminis, misalnya seperti Musda Mulia. Namanya sudah masyhur dikenal sebagai seorang feminis di Indonesia. Ia termasuk tokoh yang sangat vokal dalam menyuarakan hak-hak perempuan dan kesetaraan gender. Ia menyuarakannya melalui beberapa tulisanya, hampir semua buku yang ditulisnya mengenai persoalan perempuan dan kesetaraan gender. Ia kerap tampil di media atau di layar kaca sebagai representator pejuang kesetaraan gender. Selain itu, perjuangannya juga ditempu dengan cara mendirikan beberapa lembaga, salah satunya adalah ICRP yang mana dirinya dipercayakan memimpin lembaga tersebut.

Nama Nasaruddin Umar juga menjadi tokoh yang dapat dikategorikan sebagai seorang feminis, karena selama ini ia adalah salah seorang cendikiawan Indonesia yang sering menyuarakan keadilan gender. Pemikiran-pemikirannya tentang keadilan gender dapat dibaca dalam banyak karnyanya. Salah satunya buku yang berjudul Argumentasi Kesetaraan Gender Perspektif Al-Qur'an 
Terdapat juga nama Masdar Farid Mas'udi sebagai tokoh feminis Indonesia. Ia mulai familir sebagai tokoh feminis ketika ia berhasil menerbitkan buku yang berjudul Islam dan Hak-Hak Reproduksi Perempuan. Dalam buku tersebut, Masdar Farid Mas'udi mengatakan bahwa hak reproduksi perempuan tidak lain adalah hak yang harus dijamin pemenuhannya karena fungsi reproduksinya. Hak-hak ini secara kualitatif seimbang dengan hak-hak yang dimiliki oleh kaum laki-laki (suami/ ayah). Dan sebagai suami-istri tidak ada pihak yang secara dominan bisa dibilang lebih berat kewajiaban atau haknya dari yang lain.

Nama yang tidak boleh ketinggal disebut sebagai feminis Indonesia adalah Husein Muhammad, bahkan ia dikenal sebagai kyai feminis. Hal ini karena Husein Muhammad adalah seorang kyai sangat getol dalam membela hak-hak perempuan dan keadilan gender. Tulisan-tulisannya banyak dijadikan rujukan oleh intelektual muslim dalam meneliti Islam dan kajian gender di Indonesia. Salah satunya buku yang berjudul Fiqh Perempuan: Refleksi Kyai atas Wacana Agama dan Gender. Sebagai bentuk aplikasi dalam pembelaan terhadap perempuan, pada bulan November 2000, beliau mendirikan Fahimna Institut. Ditahun yang sama juga, ia mendirikan Pesantren Pemberdayaan Perempuan "Puan Amal Hayati.

Selain itu, nama yang tak kalah familiar sebagai tokoh feminis Indonesia adalah Faqihuddin Abdul Kodir. Kehadiran Faqihuddin dalam wacana pergulatan pemikiran kontemporer di Indonesia patut di apresiasi. Faqihuddin mencoba menafsir teks-teks agama yang bias gender dengan memberikan perspektif yang baru. Metode pendekatan yang digunakan dalam memahami teks-teks yang terkesan bias gender tersebut adalah metode Qira'ah Mubadalah. Metode ini dicetuskan oleh Faqihuddin sendiri pada tahun 2017, kemudian dibukukan pada tahun 2019 dengan judul "Qira'ah Mubadalah: Tafsir Progresif untuk Keadilan Gender dalam Islam". Qira'ah Mubadalah adalah sebuah metode progresif yang bertujuan untuk menyelesaikan problem teks-teks agama yang secara literal terkesan bias gender. Dengan menggunakan metode pendekatan tersebut dapat memberikan pemahaman baru yang ramah gender dan sekaligus membantah klaim bahwa teks-teks Islam mengandung unsur bias gender.

Untuk itu, menarik minat penulis untuk meneliti lebih jauh pemikiran feminis Faqihuddin Abdul Kodir. Dalam tulisan ini, penulis memetakan posisi pemikiran feminis Faqihuddin Abdul Kodir dalam 
dialektika pemikiran Islam kontemporer. Harapannya, penelitian ini dapat memberikan pemaparan yang jelas dan komprehensif tentang bagaimana posisi Faqihuddin Abdul Kodir dalam peta pemikiran feminis di era modoren ini.

\section{Biografi Faqihuddin Abdul Kodir}

Faqihuddin Abdul Kodir oleh para koleganya, biasa dipanggil dengan sebutan "Kang Faqih". Ia lahir, besar, berkeluarga dan bahkan hingga saat ini tinggal di Cirebon. ${ }^{1}$ Faqihuddin lahir pada tanggal 31 Desember 1971. Ayahnya bernama H. Abdul Kodir dan ibunya bernama Hj. Kuriayah. Faqihuddin adalah anak kedua dari 8 bersaudara, dan saat ini Faqihuddin merupakan suami dari Mimin Aminah dan ayah dari tiga orang anak. ${ }^{2}$

Latar belakang pendidikannya diawali dari Sekolah Dasar Negeri (SDN) Kedongdong, dan Madrasah Ibtidaiyah Wathoniyah Gintung Lor, Susukan-Cirebon dan lulus pada tahun 1983. Kemudian melanjutkan studi tingkat lanjutan di Madrasah Tsanawiyah Negeri (MTsN) Arjawinangun, Cirebon (1983-1986), lalu Madrasah Aliyah (MA) Nusantara Arjawinangun, Cirebon (1986-1989). Selama menempuh pendidikan menengah, beliau mondok di pesantren Dar al-Tauhid dibawah pengasuh KH. Ibnu Ubaidillah dan KH. Husein Muhammad. ${ }^{3}$

Setelah selesai mondok tahun 1989, Faqihuddin, meski diterima di LIPIA dan UIN Syarif Hidayatullah Jakarta, tetapi kemudian memilih tawaran beasiswa kuliah di Damaskus-Syiria, dengan mengambil double degree, Fakultas Dakwah Abu Nur (1989-1995) dan Fakultas Syari'ah Universitas Damaskus (1990-1996). Di Damaskus ini, dia belajar pada Syekh Ramadhan al-Buthi, Syekh Wahbah az-Zuhaili, serta hampir setiap

$1 \quad$ Faqihuddin Abdul Kodir, Qiras'ah Muba>dalah: Tafsir Progresif untuk Keadilan Gender dalam Islam (Yogyakarta : IRCiSoD, 2019), h. 613

2 Rafi Fauzan al-Baqi, Analisis Konseling Respirokal untuk Meningkatakan Sensitifitas Gender pada Pasangan Suami Istri : Kajian Bimbingan Islam Faqihuddin Abdul Kodir (Surabaya : UIN Sunan Ampel, 2016). h.52.

3 Rachma Vina Tsurayya, "Poligami dalam Perspektif Fakhr al-Di>n al-Razi dan Faqihuddin Abdul Kodir," dalam Jurnal Studi IImu-IImu al-Qur'an dan Hadis, Vol. 20, No. 2 (Juli 2019), h. 206 
Jumat mengikuti dzikir dan pengajian Khalifah Naqsabandiyah, Syekh Ahmad Kaftaro. ${ }^{4}$

Setelah menyelesaikan studi S1, Faqihuddin kemudian melanjutkan studinya pada jenjang master di Universitas KhortoumCabang Damaskus, tetapi belum sempat menulis tesis, ia pindah ke Malaysia. Jenjang S2 secara resmi diambil dari International Islamic University Malaysia, Fakultas Islamic Revealed Knowledge dan Human Sciences, tepatnya bidang pengembangan fiqih zakat (1996-1999). ${ }^{5}$

Sebelum melanjutkan S3, ia aktif di kerja-kerja sosial keislaman dan pengembangan masyarakat, terutama untuk pemberdayaan perempuan, selama sepuluh tahun. Setelah itu, ia melanjutkan studi S3 pada tahun 2009, di Indonesian Consortium for Religious Studies (ICRS) Universitas Gajah Mada (UGM) Yogyakarta. Tahun 2015, ia berhasil menamatkan studinya dengan menulis disertasi yang berjudul Interpretation of Hadith for Equality between Women and Men: Reading Tahrir Al-Mar'a Fi Asr Al-Risala By 'Abd Al-Halim Muhammad Abu> Shuqqah (1924-1995). ${ }^{6}$ Karya ilmiah ini membahas interpretasi Abu> Syuqqah terhadap teks-teks hadis dalam rangka kesetaraan gender dalam Islam yang merupakan cikal bakal lahirnya teori Qira'ah Mubadalah.

Faqihuddin dikenal sebagai sosok yang aktif berorganisasi. Selama di Damaskus, ia aktif di Perhimpunan Pelajar Indonesia (PPI) dan Ikatan Cendekiawan Muslim Indonesia (ICMI) orsat Damaskus. Kemudian, ketika di Malaysia, ia diamanahi sebagai Sekretaris Pengurus Cabang Istimewa Nahdlatul Ulama (PCI NU). Sepulang dari Malaysia (awal 2000), ia langsung bergabung dengan Rahima Jakarta dan Forum Kajian Kitab Kuning (FK3). Bersama dengan Husein Muhammad dan beberapa aktivis gender lain ia mendirikan Fahmina Insitute dan memimpin eksekutif selama sepuluh tahun pertama (2000-2009). Selain itu, ia juga menjadi pegiat di Lembaga Kemaslahatan Keluarga (LKK) NU Pusat

$4 \quad$ Faqihuddin Abdul Kodir, Qira>'ah Muba>dalah : Tafsir Progresif untuk Keadilan Gender dalam Islam, h. 613-614

$5 \quad$ Faqihuddin Abdul Kodir, Qira>'ah Muba>dalah: Tafsir Progresif untuk Keadilan Gender dalam Islam, h. 613

$6 \quad$ Faqihuddin Abdul Kodir, "Interpretation of Hadith for Equality Between Women and Men: Reading Tahrir Al-Mar'a Fi Asr Al-Risalah by Abd Al-Halim Muhammad Abu Shuqqa (1924-1995)" (Universitas Gajah Mada, 2015) 
serta Sekretaris Nasional Alimat (Gerakan Nasional untuk Keadilan Keluarga dalam Prespektif Islam). ${ }^{7}$

Selain itu, Faqihuddin aktif juga mengajar di IAIN Syaikh Nurjati Cirebon, dijenjang Sarjana dan Pascasarjana, di ISIF Cirebon dan mengajar di Pondok Pesantren Kebon Jambu al-Islami Babakan Ciwaringin. Sekaligus ia duduk sebagai Wakil Direktur Ma'had Aly Kebon Jambu, takhashshush fiqih dan ushul fiqh, dengan konsentrasi pada perspektif keadilan relasi laki-laki dan perempuan. ${ }^{8}$

Pada tahun 2019, Faqihuddin menerbitkan buku penting berjudul Qira'ah Mubadalah: Tafsir Progresif untuk Keadilan Gender dalam Islam (Yogyakarta: IRCiSod, 2019), Sebuah buku yang membahas bagaimana memahami teks-teks nash (al-Qur'an dan Hadis) yang menyangkut relasi laki-laki dan perempuan. Bahkan tidak cukup sampai disitu saja, Faqihuddin turut merumuskan suatu konsep baru yang disebut dengan teori Mubadalah, yaitu pendekatan dan pembacaan baru atas relasi laki-laki dan perempuan dengan melakukan reinterpretasi terhadap ayat-ayat Qur'an dan hadis. Konsep tersebut lahir dari adanya pandangan dikotomis antara laki-laki dan perempuan, ditambah sistem patriarki yang mengakar kuat di tengah masyarakat membuat cara pandang antara lakilaki dan perempuan semakin tidak ramah. Laki-laki diposisikan sebagai superior, sebaliknya perempuan sebagai inferior. ${ }^{9}$

Berkat temuan barunya tersebut, menjadikan ia diundang ke berbagai forum, baik forum nasional maupun internasional. Salah satu di antaranya Faqihuddin diundang AMAN (The Asian Muslim Action Network), bekerjasama dengan Walailak University dan Oxfam Thailand, dengan membicarakan Islam dengan pendekatan Qira'ah Mubadalah di Nongchock, Thailand. Pemikiran Faqihuddin soal Qira'ah Mubadalah ini, kemudian didiskusikan di berbagai tempat dengan tema "Majlis Mubadalah". ${ }^{10}$

Faqihuddin Abdul Kodir, Qira>'ah Muba>dalah: Tafsir Progresif untuk Keadilan Gender dalam Islam. h. 615

Faqihuddin Abdul Kodir, 60 Hadis Shahih. h. 274.

Taufan Anggoro, "Konsep Kesetaraan Gender dalam Islam: The Concept of Gender Equality in Islam", dalam Jurnal Afkaruna, Vol. 15, No. 1, Juni 2019, h. 130

10 Bangkit Media.com, "Faqihudin Abdul Kodir, Tokoh Muda NU Penggerak Majlis Mubadalh yang Mendunia" dalam 
Faqihuddin merupakan tokoh cendikiawan muslim yang terbilang sangat produktif dalam masalah penulisan, sejak tahun 2000, ia menulis rubrik "Dirasah Hadits" di Swara Rahima, majalah yang diterbitkan Rahima Jakarta untuk isu-isu pendidikan dan hak-hak perempuan dalam Islam. Di Tahun 2016, ia dipercaya sebagai anggota Tim, kontributor konsep dan buku, instruktur dan fasilitator "Bimbingan Perkawinan" yang digagas Kementrian Agama Republik Indonesia.

Sampai saat ini Faqihuddin sudah melahirkan 11 karya buku, adapun karya-karya tersebut, di antaranya: Shalawat Keadilan: Relasi Laki-laki dan Perempuan dalam Teladan Nabi (Cirebon: Fahmina, 2003), Bangga menjadi Perempuan: Perbincangan dari Sisi Kodrat dalam Islam (Jakarta: Gramedia, 2004), Memilih Monogami; Pembacaan atas alQur'an dan Hadis (Yogyakarta: LkiS, 2005), Bergerak Menuju Keadilan; Pembelaan Nabi Terhadap Perempuan (Jakarta: Rahima, 2006), Hadith and Gender Justice: Understanding the Prophetic Traditions (Cirebon: Fahmina, 2007), Manba' al-Sa'adah fi Usus Husn al-Mu'ashara fi Hayat al-Zawiyah (Cirebon: ISIF, 2012), Nabiyy alRahmah (Cirebon: ISIF dan RMS, 2013) 60 Hadis tentang Hak-hak Perempuan dalam Islam: Teks dan Inerpretasi (Yogyakarta: Graha Cendikia, 2017) Pertautan Teks da Konteks dalam Fiqh Muamalah: Isu Keluarga, Ekonomi dan Sosial (Yogyakarta: Graha Cendikia, 2017), Menguatkan Peran dan Eksistensi Keulamaan Perempuan pasca KUPI (Cirebon: Fahmina, 2018), dan Qira'ah Mubadalah: Tafsir Progresif untuk Keadilan Gender dalam Islam (Yogyakarta: Ircisod, 2019).

Buku-buku tersebut merupakan buku yang ditulis oleh Faqihuddin Abdul Kodir, selain itu masih banyak lagi karya lain seperti buku-buku yang ditulis bersama para penulis lainnya. Sedangkan buku yang pernah dieditnya antara lain; Fiqh Perempuan, Refleksi Kyai atas Wacana Agama dan Gender; Tubuh, Seksualitas, dan Kedaulatan Perempuan; Ragam Kajian Mengenai Kekerasan dalam Rumah Tangga. Selain itu, masih banyak lagi karya tulis lainnya yang dimuat dalam buletin; Swara Rahima dan jurnal; Jurnal Holistik, Jurnal Kawistara, Jurnal Equalita. Sedangkan untuk tulisan-tulisan ringan beliau dapat diakses di beberapa webiste, di antranya www.mubaadalah.com, www.mubaadalahnews.com dan lain-lain. 
Berdasarkan karya dan latar belakang Faqihuddin, penulis menyimpulkan bahwa ia merupakan tokoh yang sangat fokus dan konsen pada tema-tema gender, keadilan dan pemberdayaan perempuan. Bahkan salah satu bentuk keseriusan beliau dalam persoalan gender adalah dengan mencetuskan suatu metode interpretsi, yaitu metode Qira'ah Mubadalah. Metode ini sangat cocok dan tepat digunakan dalam memahami hadis-hadis terkait dengan persoalan gender.

\section{Pemikiran Qira'ah Mubadalah Faqihuddin Abdul Kodir}

Istilah Qira'ah Mubadalah sendiri berasal dari bahasa Arab. Secara etimologis, qira'ah memiliki akar kata yang sama dengan qur'an yang berarti bacaan. Sedangkan Mubadalah berasal dari mubadalatan ()

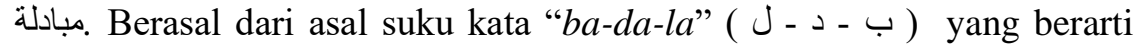
mengganti, mengubah dan menukar. ${ }^{11}$ Akar kata ini digunakan al-Qur'an sebanyak 44 kali dalam berbagai bentuk kata dengan makna seputar itu. ${ }^{12}$ Sementara itu, kata Mubadalah sendiri merupakan bentuk kesalingan (mufa'alah) dan kerjasama antara dua pihak (musyarakah) untuk makna tersebut, ${ }^{13}$ yang berarti saling mengganti, saling mengubah, atau saling menukar satu sama lain. ${ }^{14}$

Seperti halnya dalam kamus klasik, Lisan al-'Arab karya Ibnu Manzhur (w.711 H/1311 M), maupun kamus modern, seperti kamu AlMu'jam al-Wasith, mengartikan kata Mubadalah dengan tukar menukar yang bersifat timbal balik antara dua pihak. Dalam kedua kamus ini, kata "baddala-mubaddalatan" digunakan dalam ungkapan ketika seseorang mengambil sesuatu dari orang lain dan menggantikannya dengan sesuatu

11 Mahmud Yunus, Kamus Arab Indonesia (Jakarta: Mahmud Yunus Wa Dzurriyyah, 2010), h. 59.

12 Muhammad Fu'ad 'Abd al-Baqi, al-Mu'jam al-Mufahras li al-Fadz al-Qura'an (Beirut: Dar al-Fikr, 1992), h. 136

13 Musya>rakah merupakan salah satu faidah dari wazan فاعل yang memiliki arti saling (al Tasha>ruk baina ithnaini fa akthar) pihak yang satu berbuat kepada yang pihak lainnya, dan pihak lainnya juga berbuat kepada pihak yang pertama. Prinsip ini dalam ilmu Nahwu disebut Musya>rakah. Lihat Ahmad al-Hamlawi, Shadh al-'Urf fi Fanni al-Sarf (Beirut: Maktabah Al'Asriyyah, 2009), h. 49.

14 Faqihuddin Abdul Kodir, Qira'ah Mubadalah : Tafsir Progresif untuk Keadilan Gender dalam Islam, h. 59. 
yang lain. Kata ini sering digunakan untuk aktivitas pertukaran, perdagangan, dan bisnis. ${ }^{15}$

Dalam kamus modern lain, Al-Mawrid, untuk Arab-Inggris, karya Dr. Rohi Baalbaki, kata Mubadalah diartikan muqabalah bi al-mitsl. Yaitu menghadapkan sesuatu dengan padanannya. Kemudian, diterjemahkan ke dalam bahasa Inggris dengan beberapa makna; reciprocity, reciprocation, repayment, requital, paying back, returning in kind or degree. Sementara dalam kamus besar bahasa Indonesia, kata "kesalingan" (terjemah dari mubdalah dan reciprocity) digunakan untuk hal-hal "yang menggunakan makna timbal balik". ${ }^{16}$

Adapun secara terminologis, pengertian Qira'ah Mubadalah menurut Faqihuddin adalah sebuah metode pendekatan untuk melakukan interpretasi terhadap teks-teks sumber Islam, baik al-Quran maupun hadis dengan perspektif kesalingan antara laki-laki dan perempuan. Sebuah perspektif dan pemahaman yang melihat relasi antara laki-laki dan perempuan dengan kaca mata yang egaliter dan menjunjung tinggi semangat kemitraan, kerja sama, kesalingan dan timbal balik. Faqihuddin menambahkan bahwa dalam diskursus Qira'ah Mubadalah, baik laki-laki maupun perempuan dipadang memiliki posisi yang sama. Tidak boleh memandang segala sesuatu hanya dengan perspektif salah satu jenis kelamin. Demikian karena keduanya sama-sama disapa oleh teks agama dan harus tercakup dalam kandungan makna teks tersebut. ${ }^{17}$

Sehingga secara garis besar, Qira'ah Mubadalah adalah suatu metode bagaimana cara menyapa, menyebut, mengajak laki-laki dan perempuan dalam suatu teks yang hanya menyebutkan jenis kelamin tertentu dengan cara memahami gagasan utama atau makna besar, yang bisa diterapkan untuk keduanya, laki-laki dan perempuan dalam suatu teks. Dengan begitu, tidak hanya laki-laki atau perempuan saja tetapi keduanya bisa menjadi subjek atau pelaku dalam teks tersebut. ${ }^{18}$

Muhammad bin Mukrim Ibn Manzur, Lisan Al-'Arab, Vol. 11 (Bairut: Dar Sadir, 1414), h. 49. ; Syauqi Dhaif, Al-Mu'jam al-Wasith (Mesir: Maktabah Syurouq ad-Dauliyah, 2011), h. 88 Rohi Baalbaki, Al-Mawrid: a Modern Arabic-English Dictionary (Beiru>t: Dar El-Ilm Limalayin, 2011), h.101

17 Faqihuddin Abdul Kodir, Qira'ah Mubadalah: Tafsir Progresif untuk Keadilan Gender dalam Islam, h. 59.

Lukman Budi Santoso, "Eksistensi Peran Perempuan Sebagai Kepala Keluarga: Telaah Terhadap Counter Legal Draf-Kompilasi Hukum Islam dan 
Qira'ah Mubadalah menurut Faqihuddin bertujuan menyeimbangkan relasi yang ada di antara laki-laki dan perempuan. Melakukan perbaikan dari relasi yang hirarkis seperti yang cenderung terlihat saat ini, menuju relasi yang egaliter, sehingga diharapkan tidak ada lagi bentuk superioritas laki-laki dan inferioritas perempuan maupun sebaliknya. Hal ini dilakukan meninjau pada ketimpangan dalam hubungan sesama manusia akan berakibat pada kerugian salah satu pihak, karena hak-haknya sebagai sesama makhluk Tuhan terancam. Bias gender sebenarnya bukan hanya merugikan salah satu pihak, tapi juga bisa merugikan pihak lainnya. ${ }^{19}$

Qira'ah Mubadalah sengaja dihadirkan untuk melengkapi dinamika teks dan realitas dalam tradisi keislaman yang selama ini masih sedikit mempresentasikan kesadaran bahwa perempuan adalah subjek yang sama dengan laki-laki. Metode interpretasi Mubadalah merupakan interaksi antara teks dan realitas, yang diharapkan bisa memberi makna secara konstruktif bagi realitas kehidupan perempuan serta dapat mengangkat prinsip-prinsip relasi antara laki-laki dan perempuan. Metode ini digunakan sebab dalam teks-teks Islam terkadang hanya lakilaki yang disapa oleh teks. Atau ada juga yang hanya menyapa perempuan. Sehingga secara tekstual, ayat atau hadis tersebut hanya berlaku untuk subjek yang disapa oleh teks tersebut. ${ }^{20}$

Nur Rofiah menegaskan bahwa Qira'ah Mubadalah merupakan cara pandang relasi antara laki-laki dan perempuan yang bersifat kemitraan dan kerja sama. Kemitraan antara laki-laki dan perempuan disini bersifat luas, yang tujuannya adalah kemaslahatan kehidupan umat manusia. Metode ini dalam prakteknya berupaya menggali makna teks (Qur'an dan hadis) agar dapat diterapkan kepada laki-laki dan perempuan sekaligus. Lebih lanjut, dia menjelaskan bahwa jika sebuah teks hanya menyapa salah satu jenis kelamin, maka diperlukan kajian lebih

Qira'ah Mubadalah", dalam Marwah: Jurnal Perempuan, Agama dan Jender, Vol. 18, No. 2, 2019, h. 113

19 Faqihuddin Abdul Kodir, Qira'ah Mubadalah: Tafsir Progresif untuk Keadilan Gender dalam Islam, h. 59.

20 Lukman Hakim, "Corak Feminisme Post-Modernis dalam Penafsiran Faqihuddin Abdul Kodir" dalam Jurnal Studi IImu-IImu al-Qur'an dan Hadis, Vol. 21, No. 1, Januari 2020, h. 247 
komprehensif agar didapatkan makna yang dapat berlaku untuk keduanya. $^{21}$

Lebih mudahnya, Qira'ah Mubadalah menekankan bahwa jika senyum, keramahan, melayani, dan segala tindakan yang menyenangkan harus dilaksanakan keduanya. Baik dilakukan suami pada istrinya, maupun istri kepada suaminya. Prinsip Mubadalah (kesalingan) keberlakuannya mencakup semua nilai dan prinsip-prinsip kesetaraan dan kemanusiaan. Kesetaraan dan kemanusiaan menjadi dua pondasi penting untuk mewujudkan kemaslahatan, kerahmatan, dan keadilan. Sebenarnya, buku-buku atau karya tulis yang membahas seputar reinterpretasi teksteks Islam seputar relasi laki-laki dan perempuan sudah cukup banyak. Di Indonesia sendiri beberapa karya-karya ilmiah telah melakukan upaya tersebut.

Sebut saja misalnya buku yang berjudul Perempuan di Lembaran Suci karya Ahmad Fudhaili yang terbit pada tahun 2013. ${ }^{22}$ Perbedaannya dengan karya Faqihuddin ini yang paling mencolok ialah pada adanya tawaran metode. Selain itu, reinterpretasi yang dilakukan oleh Faqihuddin juga mengalami pengembangan, khususnya yang dipaparkan pada bab keenam bukunya ini. Pada bab keenam ini, Faqihuddin berupaya melakukan reinterpretasi teks-teks yang membicarakan karir perempuan dalam isu-isu publik. Suatu pembahasan yang masih belum mendapat perhatian lebih dari para pengkaji, yang pada kesempatan ini turut dibahas dalam buku Qira'ah Mubadalah karya Faqihuddin Abdul Kodir ini.

Faqihuddin menyebutkan bahwa metode pemaknaan mubadalah didasarkan pada tiga premis, yaitu (1) Bahwa Islam hadir untuk laki-laki dan perempuan, sehingga teks-teks pun harus menyasar keduanya. (2) Bahwa prinsip relasi antara keduanya adalah kerja sama dan kesalingan, bukan hegemoni dan kekuasaan; (3) Bahwa teks-teks Islam itu terbuka

Hal ini diutarakan oleh Nur Rofiah dalam prolog buku Qira'ah Mubadalah karya Faqihuddin Abdul Kodir. Prolog tersebut dengan judul "Qira'ah Mubadalah sebagai Syarat Tafsir Agama Adil Gender. Lihat Faqihuddin Abdul Kodir, Qira'ah Mubadalah: Tafsir Progresif untuk Keadilan Gender dalam Islam, h. 28. 
untuk dimaknai ulang agar memungkinkan kedua premis sebelumnya tercermin dalam setiap kerja interpretasi. ${ }^{23}$

Berdasarkan ketiga premis tersebut, kerja metode pemaknaan Mubadalah berproses untuk menemukan gagasan-gasan utama dari setiap teks yang dibaca agar selalu selaras dengan prinsip-prinsip Islam yang universal dan berlaku bagi seluruh manusia, baik laki-laki maupun perempuan. ${ }^{24}$

Faqihuddin menjelaskan bahwa teknik praktis dalam pengoperasian Qira'ah Mubadalah sendiri ada tiga langkah yang bersifat kronologis. Artinya, tiga langkah ini dilalui dengan berurutan. Meskipun bagi seseorang yang sudah sampai level tertentu, bisa memulai di langkah kedua, atau bahkan langsung pada langkah ketiga. Ketiga langka tersebut adalah sebagai berikut:

Pertama, yaitu menemukan dan menegaskan prinsip-prinsip ajaran Islam dari teks-teks yang bersifat universal sebagai pondasi pemaknaan. Baik prinsip yang bersifat umum melampaui seluruh tema (al-mabadi) maupun yang bersifat khusus untuk tema tertentu (al-qawaid). Misalnya, ajaran mengenai keimanan yang menjadi ponasi setiap amal, bahwa amal kebaikan akan dibalas pahala dan kebaikan tanpa melihat jenis kelamin, tentang keadilan yang harus ditegakan, tentang kemaslahatan dan kerahmatan yang harus diterbarkan. ${ }^{25}$

Langkah pertama inilah yang merupkan landasan utama dalam pemaknaan terhadap teks-teks yang akan diinterpretasikan. Langkah ini sangat penting untuk digunakan dalam prinsip-prinsip nilai ketauhidan, keadilan dan universal bagi semua manusia, baik laki-laki ataupun perempuan.

Kedua, yaitu menemukan gagasan utama yang terekam dalam teksteks yang akan diinterpretasikan. Dalam hal ini, teks-teks relasional yang sudah menyebutkan peran laki-laki dan perempuan, kebanyakan merupakan sesuatu yang bersifat implementatif, praktis, parsial dan hadir

Faqihuddin Abdul Kodir, Qira'ah Mubadalah : Tafsir Progresif untuk Keadilan Gender dalam Islam. h. 196 Gender dalam Islam. h. 196.

25 Faqihuddin Abdul Kodir, Qira'ah Mubadalah: Tafsir Progresif untuk Keadilan Gender dalam Islam. h. 200. 
sebagai sebuah contoh pada ruang dan waktu tertentu bagi prinsip-prinsip Islam. Langkah kedua ini, secara sederhana bisa dilakukan dengan menghilangkan subjek dan objek yang ada dalam teks. Lalu, predikat dalam teks menjadi makna atau gagasan yang akan kita Mubadalah-kan antara dua jenis kelamin.

Ketiga, langkah ketiga menurunkan gagasan dari yang ditemukan dari teks (yang lahir dari proses langkah kedua) kepada jenis kelamin yang tidak disebutkan dalam teks. Dengan demikian, teks tersebut tidak akan berhenti pada satu jenis kelamin, melainkan mencakup keduanya, baik laki-laki maupun perempuan. Sehingga, metode ini menegaskan bahwa teks untuk laki-laki ada juga untuk perempuan, dan teks perempuan ada juga untuk laki-laki, selama dapat menemukan makna gagasan utama dari suatu teks tersebut yang bisa mengaitkan dan berlaku untuk keduanya. ${ }^{26}$

\section{Posisi Faqihuddin Abdul Kodir dalam Peta Studi Islam Kontemporer}

Faqihuddin Abdul Kodir adalah salah satu dari sekian jumlah cendikiawan Muslim Indonesia yang memfokuskan diri pada isu-isu keadilan gender. Oleh karena itu, ia dapat diidentifikasi sebagai seorang feminis, lebih tepatnya disebut sebagai Feminis Muslim. Hal ini dasarkan pada pengertian Feminis Muslim, yaitu mereka yang mendorong keadilan gender dan persamaan hak dengan cara berijtihad bahwa sistem patriarki yang ada selama ini tidak sesuai dengan prinsip-prinsip al-Qur'an dan hadis. Mereka menggunakan interpretasi al-Qur'an dan hadis maupun teks-teks keagamaan lain untuk mendapatkan pandangan yang holistik mengenai prinsip egaliter dalam Islam. ${ }^{27}$

Oleh karena itu, berdasarkan pengertian di atas maka posisi Faqihuddin dalam peta studi keislaman dapat dikelompokkan sebagai Feminis Muslim. Hal ini serupa dengan tokoh-tokoh feminis yang lain

Faqihuddin Abdul Kodir, Qira'ah Mubadalah: Tafsir Progresif untuk Keadilan Gender dalam Islam. h. 202.

27 Margot Badran, Feminism in Islam: Secular and Religious Convergences (England: Oxford, 2009), h. 9 ; Neng Dara Affiah, Muslimah Feminis: Penjelasan Multi Identitas (Jakarta: Nalar, 2009), h. 12 ; Mai Yamani, Feminisme dan Islam: Perspektif Hukum dan Sastra (Bandung: Yayasan Nuansa Cendekia, 1999), h. 3 
yang terlebih dahulu telah diidentifikasi sebagai seorang feminis, seperti Fatimah Mernissi, Qasim Amin, Amina Wadud, Asghar Ali Engineer, Nawal El-Saadawi, Riffat Hasan, dan masih banyak lagi yang lain. Ketika dilokalisir di Indonesia, maka akan ditemukan sejumlah tokoh seperti Musda Mulia, Nasaruddin Umar, Masdar Farid Mas'udi, Husein Muhammad, dan lain-lain.

Label feminis muslim memang tepat dialamatkan pada diri Faqihuddin dengan berdasarkan pada aktifitasnya selama ini yang banyak concern pada perjuangan isu-isu keadilan gender. Nampak terlihat bahwa ia tidak pernah lelah membela perempuan. Ia berjuang mendongkrak kemapanan pemahaman relasi gender yang telah lama menggurita di tengah masyarakat dengan sebuah sistem budaya yang patriarki. Perjuangan Faqihuddin ditempuh dengan banyak cara dan melalui beberapa jalur demi terwujudnya suatu sistem tatanan masyarakat yang berkeadilan gender. Dalam hal ini penulis membagi aktifitas perjuangan keadilan gender yang dilakukan oleh Faqihuddin dengan empat model, yaitu: Pertama, melakukan pemberdayaan kaum perempuan dengan bergabung pada pusat-pusat studi dan LSM yang fokus pada isu keperempuanan, seperti Fahmina Institute, ALIMAT, Women Crisis Center (WCC) Lembaga Kemaslahatan Keluarga (LKK) NU Pusat, dan lain-lain.

Kedua, menginisiasi sejumlah acara-acara yang bertajuk perjuangan keadilan gender, seperti pelatihan, workshop, seminar, dimana ia aktif menjadi pembicara dalam forum-forum tersebut. Bahkan akhir-akhir ini ia sering menyampaikan ide dan gagasannya dalam bentuk ngaji online, baik melalui Facebook, Instgram, You Tube, dan media sosial yang lain. Ketiga, berjuang melalui karya-karya tulis dengan beragam tema dan genre. Sampai saat ini Faqihuddin sudah melahirkan 11 buku yang semuanya berkaitan masalah perempuan dan keadilan gender. Keempat, melakukan reinterpretasi terhadap teks-teks keagamaan, baik al-Qu'ran, hadis maupun literatur klasik yang secara literal-tekstual mendiskreditkan perempuan. Bahkan ia tidak hanya melakukan reinterpretasi tapi juga menawarkan sebuah metode sebagai alat pisau bedah dalam membaca teks-teks yang terkesan bias gender.

Empat aktivitas di atas menggambarkan betapa seorang Faqihuddin sangat peduli terhadap isu-isu seputar relasi laki-laki dan perempuan. Oleh karena itu, tidak salah kalau ia digelari sebagai seorang feminis. 
Kipranya dalam memperjuangkan keadilan dan pemenuhan hak-hak perempuan tidak diragukan lagi. Ia hampir mencurahkan seluruh waktunya dalam melawan budaya patriarki yang sudah lama menggurita di masyarakat.

Gelar sebagai feminis muslim yang diberikan pada dirinya menjadikan ia mengikuti jejak langkah gurunya, Husain Muhammad. Ia adalah guru yang sangat berpengaruh dalam membentuk dirinya sehingga ia menjadi seperti sekarang ini. Husain Muhammad adalah salah satu kyai di Indonesia yang fokus pada perjuangan hak perempuan dan keadilan gender. Bahkan, Husain Muhammad dijuluki sebagai kyai feminis karena ia disebut satu-satunya kyai di Indonesia yang mengeksplorasi isu-isu perempuan melalui kitab-kitab kuning (turats) kemudian diajarkan kepada santri-santrinya di Pondok Pesantren tempat ia mengajar. Oleh karena itu, sebagai seorang yang mewarisi keilmuan gurunya, tidak salah kalau Faqihuddin juga dapat disebut sebagai feminis, yang lebih tepatnya disebut sebagai feminis muslim. ${ }^{28}$

Citra feminis muslim yang dilekatkan pada Faqihuddin berawal dari pengalaman pendidikan yang ditempuhnya sejak di pondok pesantren. Pendidikan tradisional yang dikenyamnya di pesantren membuatnya memiliki minat yang besar terhadap ilmu agama Islam. Sedangkan minatnya kepada feminisme juga berawal dari masa itu. Beberapa kali ia berhadapan dengan pertanyaan yang datang dari gurunya sehingga membuatnya "galau" dan "gundah". Salah satunya, mengenai persoalan haid pada perempuan yang dianggapnya pelik. Selain itu, ia juga mengamati dari realita yang terjadi di lingkungannya di mana beberapa teman perempuannya yang dinikahkan secara paksa oleh orang tuanya, hingga terputus pendidikannya. ${ }^{29}$

Ketika melanjutkan pendidikannya di Damaskus, pada fase ini, Faqihuddin mengakui belum merasa nyaman dengan kajian feminis terhadap isu-isu yang diyakininya sebagai kebenaran Islam. Ia pernah

Rafi Fauzan Al-Baqi, “Analisis Konseling Resiprokal Untuk Meningkatkan Sensitifitas Gender Pada Pasangan Suami Istri: Kajian Bimbingan Konseling Islam Faqihuddin Abdul Kodir" dalam http://diglib.uinsby.ac.id/5495/. Diakses pada tangga 17 Juni 1991.

Rafi Fauzan Al-Baqi, "Analisis Konseling Resiprokal Untuk Meningkatkan Sensitifitas Gender Pada Pasangan Suami Istri: Kajian Bimbingan Konseling Islam Faqihuddin Abdul Kodir" dalam http://diglib.uinsby.ac.id/5495/. Diakses pada tangga 17 Juni 1991. 
membaca tulisan-tulisan dari Wardah Hafiz, Riffat Hassan, dan Budi Munawar Rahman yang sampai ke sana. Namun, ia cenderung resisten terhadap pandangan mereka. Sebaliknya, ia justru bersimpati terhadap pandangan "membiarkan berbeda" yang ditawarkan oleh Ratna Megawangi. Hingga akhirnya ia membaca kitab Tahrir al-Mar'ah fi Asr ar Risalah, karya Abd al-Halim Abu Syuqqah yang menjadi titik balik ia bersimpati pada isu-isu perempuan. ${ }^{30}$

Ketertarikan Faqihuddin pada ide-ide feminis semakin kuat setelah ia balik ke Tanah Air dan bertemu gurunya, Husain Muhammad. Ia diminta oleh gurunya untuk ikut terlibat aktif dalam pemberdayaan perempuan agar ilmunya dapat digunakan. Akhirnya, setelah ia terlibat banyak dalam aktivitas tersebut, ia mulai menjadi benar-benar sadar bahwa telah terjadi ketimpangan relasi antara laki-laki dan perempuan. Selama ini ketimpangan tersebut hanya diketahui melalui dari kitab-kitab yang ia baca. Namun, ternyata realitas dilapangan ketimpangan itu benarbenar terjadi. Walhasil, ia akhirnya bertekad mengabdikan dirinya pada kerja-kerja feminis dalam rangka memperjuangkan hak-hak perempuan dan keadilan gender. ${ }^{31}$

Pada dasarnya, feminisme terbagi dalam beberapa bagian, paling tidak dapat dibagi menjadi empat, yaitu feminis liberal, ${ }^{32}$ feminis

Rafi Fauzan Al-Baqi, "Analisis Konseling Resiprokal Untuk Meningkatkan Sensitifitas Gender Pada Pasangan Suami Istri: Kajian Bimbingan Konseling Islam Faqihuddin Abdul Kodir" dalam http://diglib.uinsby.ac.id/5495/. Diakses pada tangga 17 Juni 1991.

31 Rafi Fauzan Al-Baqi, "Analisis Konseling Resiprokal Untuk Meningkatkan Sensitifitas Gender Pada Pasangan Suami Istri: Kajian Bimbingan Konseling Islam Faqihuddin Abdul Kodir" dalam http://diglib.uinsby.ac.id/5495/. Diakses pada tangga 17 Juni 1991.

Feminis liberal adalah varian pertama dari feminsi besar. Sepeti namanya, feminisme liberal mengambil asumsi-asumsi dasar teori liberalisme.berasumsi bahwa pada dasarnya tidak ada perbedaan antara laki-laki dan perempuan, feminisme liberalisme lebih memfokuskan pad perubahan undang-undang yang menempatkan suami sebagai kepala keluarga.Konsep kepala keluarga konvensional yang berlaku secara universal adalah suami sebagai pemberi nafkah dan pelindung keluarga. Hal ini menurut feminisme liberal tidak sesuai dengan konsep kebebasan individu untuk mandiri dan menentukan jalan mereka sendiri, konsep kepala keluarga ini menurut mereka dapat membuat perempuan terus tergantung pada lakilaki. Lihat Alfian Rokhmansyah, \Pengantar Gender dan Feminisme: 
sosialis, ${ }^{33}$ feminis radikal, ${ }^{34}$ dan feminis post-modernis. ${ }^{35}$ Lukman Hakim dalam tulisannya yang berjudul Corak Feminisme Post-Modernis dalam Penafsiran Faqihuddin Abdul Kodir memasukkan Faqihuddin dalam kelompok feminis post-modernis. Lukman menemukan bahwa rekonstruksi makna yang dilakukan oleh Faqihuddin, pada dasarnya didorong oleh usaha untuk melepaskan tatanan simbol dalam teks yang dipahami hanya dalam bentuk literalnya. Hal ini mencerminkan adanya kesesuaian argumentasi Faqihuddin dengan kalangan feminisme post-

Pemahaman Awal Kritik Sastra Feminisme (Yogyakarta: Garudhawaca, 2016), h. 50

33 Gerakan feminisme sosialis adalah gerakan feminisme yang mengadopsi teori Praxis Marxisme, yakni teori penyadaran pada kelompok tertindas agar para perempuan sadar bahwa mereka merupakan kelas yang tidak diuntungkan. Penyebab penindasan perempuan dihubungkan dengan tipe organisasi sosial, khususnya tatanan perekonomian. Timbulnya penyadaran ini akan membuat para perempuan bangkit emosinya, dan secara kelompok diharapkan untuk mengadakan konflik langsung dengan kelompok (laki-laki). Semakin tinggi tingkat konflik dominasi, diharapkan dapat meruntuhkan sistem patriarki. Lihat lan Buchanan, Socialist Feminism (Oxford University Press, 2011), h. 155

Feminis radikal adalah sudut pandang feminis yang ingin perubahan secara radikal dalam masyarakat dengan menghapuskan semua bentuk supremasi laki-laki dalam kontek sosial dn ekonomi. Teori feminisme radikal berkembang pesat di Amerika Serikat pada kurun waktu 1960-an sampai 1970-an, feminisme radikal lebih memfokuskan serangannya pada keberadaan institusi keluarga dan sistem patriarki. Lembaga perkawinan adalah lembaga formalitas untuk menindas perempuan, sehingga tugas utama para radikal feminis adalah menolak institusi keluarga.11 Feminisme radikal cenderung membenci laki-laki sebagai individu dan mengajak perempuan untuk mandiri, bahkan tanpa perlu keberadaan laki-laki dalam kehidupan perempuan. Ellen Willis, "Radical Feminism and Feminist Radicalism", dalam Wesleyan University Press, 1992, h. 117

Feminis post-modernisme dikenal sebagai gerakan feminis yang dilakukan oleh akademisi. Disebut demikian karena aliran ini lebih menekankan studistudi akademik khsusunya pada kajian teks, analisis bahasa, dan interpretasi. Sehingga yang menjadi perhatian dari aliran feminis post-modernisme adalah mereka mengkritik teks-teks yang selama ini banyak diproduksi oleh kaum laki-laki. Menurutnya, karya-karya tulisan yang ada selama ini bercorak lebih maskulin sehingga melahirkan gagasan yang bias gender. Oleh karena itu, sebagai jalan keluar teks-teks tersebut harus didekonstruksi dengan cara kerangka berfikri feminim sebagai jalan mewujudkan kesetaraan gender. Lihat Jean Kantambu Latting, "Post-Modern Feminist Theory and Social Work: A Deconstruction" dalam Social Work, Vol. 40, No, 6, (November 1992), h. 489 
modernis yang menolak setiap istilah yang mengindikasikan adanya subordinasi perempuan terhadap laki-laki. ${ }^{36}$

Oleh karena itu, berdasarkan pada uraian penjelasan di atas, maka dapat ditarik sebuah kesimpulan bahwa posisi Faqihuddin Abdul Kodir dalam peta studi Islam Kontemporer yang paling tepat dapat ditempatkan sebagai faminis muslim yang berhaluan post-modernisme yang berusaha keluar dari pola pola-penafsiran klasik.

\section{Kesimpulan}

Faqihuddin Abdul Kodir lahir di Cirebon 31 Desember 1971. Pendidikannya dimulai di SDN Kedongdong dan lulus tahun 1983. MTsN Arjawinangun, Cirebon (1983-1986), Madrasah Aliyah (MA) Nusantara Arjawinangun, Cirebon (1986-1989). Selama menempuh pendidikan menengah, beliau mondok di pesantren Dar al-Tauhid dibawah pengasuh KH. Ibnu Ubaidillah dan KH. Husein Muhammad. Setelah selesai mondok tahun 1989, Faqihuddin ke Damaskus-Syiria untuk kuliah dengan mengambil double degree, Fakultas Dakwah Abu Nur (1989-1995) dan Fakultas Syari'ah Universitas Damaskus (19901996). Setelah menyelesaikan studi S1, Faqihuddin kemudian melanjutkan studinya pada jenjang master di International Islamic University Malaysia, Fakultas Islamic Revealed Knowledge dan Human Sciences, (1996-1999). Selanjutnya, pada tahun 2009 Faqihuddin melanjutkan studi S3nya pada tahun 2009 di Universitas Gajah Mada (UGM) Yogyakarta dan dapat menyelesaikannya pada tahun 2015.

Qira'ah Mubadalah berasal dari bahasa Arab. Secara etimologis, qira'ah memiliki akar kata yang sama dengan qur'an yang berarti bacaan. Sedangkan Mubadalah berasal dari mubadalatan ( مبادلة). Berasal dari asal suku kata ba-da-la yang berarti mengganti, mengubah dan menukar. Secara terminologi, Qira'ah Mubadalah adalah sebuah metode pendekatan untuk melakukan interpretasi terhadap teks-teks sumber Islam, baik al-Quran maupun hadis dengan perspektif kesalingan antara laki-laki dan perempuan. Metode pemahaman yang melihat relasi antara laki-laki dan perempuan dengan kaca mata yang egaliter dan

36 Lukman Hakim, "Corak Feminisme Post-Modernis dalam Penafsiran Faqihuddin Abdul Kodir" dalam Jurnal Studi IImu-IImu al-Qur'an dan Hadis, Vol. 21, No. 1 (Januari 2020), h. 238 
menjunjung tinggi semangat kemitraan, kerja sama, kesalingan dan timbal balik

Faqihuddin dapat diidentifikasi sebagai seorang feminis, lebih tepatnya disebut sebagai Feminis Muslim. Hal ini dasarkan pada pengertian Feminis Muslim, yaitu mereka yang mendorong keadilan gender dan persamaan hak dengan cara berijtihad bahwa sistem patriarki yang ada selama ini tidak sesuai dengan prinsip-prinsip al-Qur'an dan hadis. Mereka menggunakan interpretasi al-Qur'an dan hadis maupun teks-teks keagamaan lain untuk mendapatkan pandangan yang holistik mengenai prinsip egaliter dalam Islam. Oleh karena itu, berdasarkan pengertian di atas maka posisi Faqihuddin dalam peta studi keislaman dapat dikelompokkan sebagai Feminis Muslim.

Selain itu, posisi Faqihuddin Abdul Kodir dalam peta studi Islam Kontemporer yang paling tepat dapat ditempatkan sebagai faminis muslim yang berhaluan post-modernisme yang berusaha keluar dari pola pola-penafsiran klasik. 


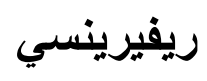

Afandi, Agus. "Bentuk-Bentuk Perilaku Bias Gender" dalam Lentera: Journal of Gender and Children Studies, Vol I, no 1, Desember 2019.

Al-Ba>qi>, Muhammad Fu'ad 'Abd. Al-Mu'jam al-Mufahras li al-Fadz al-Qura'an, Beirut: Dar al-Fikr, 1992.

Al-Baqi, Rafi Fauzan. Analisis Konseling Respirokal untuk Meningkatakan Sensitifitas Gender pada Pasangan Suami Istri : Kajian Bimbingan Islam Faqihuddin Abdul Kodir, Surabaya : UIN Sunan Ampel, 2016.

Al-Buthi, Muhammad Sa'id Ramadhan. Dawabith al-Maslahat fi alSyari'ah al-Islami, Beirut: Muassisah al-Risalah, 1977.

Al-H\}amlawi, Ahmad. Shadh al- 'Urf fi Fanni al-Sarf, Beirut: Maktabah Al-'Asriyyah, 2009.

Allawi, Muhammad Bary dkk, Gender dan Orientasi Memilih Pasangan Hidup: Analisis Orientasi Perempuan Memilih Pasangan Hidup dalam Perspektif Kesetaraan Gender, Bandung: UIN Sunan Gunung Djati, 2018

Al-Thabari, Jarir. Tafsir al-Tabari al-Musamma Jami' al-Bayan fi Ta 'wil al-Qur'an, Madinah: Ummu al-Qura, t.th.

Anggoro, Taufan. "Konsep Kesetaraan Gender dalam Islam: The Concept of Gender Equality in Islam", dalam Jurnal Afkaruna, Vol. 15, No. 1, Juni 2019.

Baalbaki, Rohi. Al-Mawrid: a Modern Arabic-English Dictionary, Beirut: Dar El-Ilm Limalayin, 2011.

Bukhari, Imam. Shahih Bukhari, Beirut: Dar Ibnu Katsir, 1987 M / 1407 $\mathrm{H}$.

Dhaif, Syauqi. Al-Mu'jam al-Wasith, Mesir: Maktabah Syurouq adDauliyah, 2011.

Fudhaili, Ahmad. Perempuan di Lebaran Suci: Kritik atas Hadis-Hadis Shahih, Jakarta: Transpustaka, 2013.

Gusmian, Islah. Mengapa Nabi Berpoligami: Mengungkap Kisah Kehidupan Rumah Tangga Nabi Bersama 11 Istrinya, Yogyakarta: Pustaka Marwa, 2007.

Hakim, Lukman. "Corak Feminisme Post-Modernis dalam Penafsiran Faqihuddin Abdul Kodir" dalam Jurnal Studi Ilmu-Ilmu alQur'an dan Hadis, Vol. 21, No. 1, Januari 2020. 
Hana, Leyla. Perjanjian Yang Kuat: Mitsaqan Ghalizha, Jakarta: PT Elex Media Komputindo, 2013

Iqbal, Muhammad. Psikologi Pernikahan: Menyelami Rahasia Pernikahan, Depok: Gema Insani, 2018.

Jalaluddin As-Suyuthi dan Jalaluddin Al-Mah\}alli, Tafsir Jalalain, t.tp: Dar al-Ihya, t.th.

Khaidir Masrizal, "Penilaian Tingkat Fertilitas dan Penatalaksanaanya Pada Pria" dalam Jurnal Kesehatan Masyarakat, September 2006.

Kodir, Faqihuddin Abdul "Interpretation of Hadith for Equality Between Women and Men: Reading Tahrir Al-Mar'a Fi Asr AlRisalah by Abd Al-Halim Muhammad Abu Shuqqa (19241995) ’, Universitas Gajah Mada, 2015, Faqihuddin Abdul Kodir. Qira'ah Mubadalah: Tafsir Progresif untuk Keadilan Gender dalam Islam, Yogyakarta : IRCiSoD, 2019.

60 Hadis Shahih. Yogyakarta: Diva Press, 2019.

---------, Faqihuddin Abdul, Sunnah Monogami: Mengaji Alquran dan Hadis, Malaysia: Penerbit USM, 2017.

Manshur, Ali. Hukum dan Etika Pernikahan dalam Islam, Malang: UB Press, 2017.

Manzur, Muhammad bin Mukrim Ibn. Lisan Al-'Arab, Vol. 11, Bairut: Dar Sadir, 1414.

Mas'udi, Masdar Farid. Islam dan Hak-Hak Reproduksi Perempuan: Dialog Fiqih Pemberdayaan, Bandung: Mizan, 1997.

Mulia, Musda. Mengupas Seksualitas: Mengerti Arti, Fungsi, dan Problematika Seksual Manusia di Era Kita (Jakarta: PT Serambi Ilmu Semesta, 2015), h. 34

Muslim, Imam. Shahih Muslim, Beirut: Dar al-Afaq al-Jadidah, 1334.

Nugroho, Anjar. Fikih Perempuan Kontemporer: Hak-Hak Perempuan dalam Perkawinan, Purwekerto: UM Purwekerto Press, 2020

Santoso, Lukman Budi. "Eksistensi Peran Perempuan Sebagai Kepala Keluarga: Telaah Terhadap Counter Legal Draf-Kompilasi Hukum Islam dan Qira'ah Mubadalah", dalam Marwah: Jurnal Perempuan, Agama dan Jender, Vol. 18, No. 2, 2019.

Tsurayya, Rachma Vina, "Poligami dalam Perspektif Fakhr al-Din alRazi dan Faqihuddin Abdul Kodir," dalam Jurnal Studi Ilmu-Ilmu al-Qur'an dan Hadis, Vol. 20, No. 2 Juli 2019. 
Ulfah Zakiyah

Walby, Sylvia. Teorisasi Ptriarki, Yogyakarta: Jalasutra, 2014.

Yudisia, Sinta. Seksologi Pernikahan Islami, Surakarta: Indiva Media Kreasi, 2018.

Yunus, Mahmud. Kamus Arab Indonesia, Jakarta: Mahmud Yunus Wa Dzurriyyah, 2010 